\section{Early mortality after neonatal surgery: analysis of risk factors in an optimized health care system for the surgical newborn}

Dora Catré',II,III

Maria Francelina Lopes ${ }^{1,1,1,1 \mathrm{~V}}$

Angel Madrigalv

Bárbara Oliveiros $^{\mathrm{VI}}$

Joaquim Silva VianavII

\section{António Silvério Cabrita"}

'Centro de Formação e Investigação Clínica, Centro Hospitalar e Universitário de Coimbra - Coimbra, Portugal.

"School of Medicine, Universidade de Coimbra - Coimbra, Portugal.

"'Department of Anesthesiology, Centro Hospitalar Tondela-Viseu - Viseu, Portugal.

"vepartment of Pediatric Surgery, Pediatric Hospital, Centro Hospitalar e Universitário de Coimbra - Coimbra, Portugal.

vDepartment of Pediatric Anesthesiology, Pediatric Hospital, Centro Hospitalar e Universitário de Coimbra - Coimbra, Portugal.

v'Department of Biostatistics and Medical Informatics, School of Medicine, Universidade de Coimbra - Coimbra, Portugal.

VIISchool of Health Sciences, Universidade da Beira Interior - Covilhã, Portugal.

\section{Abstract}

Objective: Anesthetic and operative interventions in neonates remain hazardous procedures, given the vulnerability of the patients in this pediatric population. The aim was to determine the preoperative and intraoperative factors associated with 30-day post-operative mortality and describe mortality outcomes following neonatal surgery under general anesthesia in our center. Methods: Infants less than 28 days of age who underwent general anesthesia for surgery during an 11-year period (2000 - 2010) in our tertiary care pediatric center were retrospectively identified using the pediatric intensive care unit database. Multiple logistic regression was used to identify independent preoperative and intraoperative factors associated with 30-day post-operative mortality. Results: Of the 437 infants in the study (median gestational age at birth 37 weeks, median birth weight 2,760 grams), 28 (6.4\%) patients died before hospital discharge. Of these, 22 patients died within the first post-operative month. Logistic regression analysis showed increased odds of 30-day postoperative mortality among patients who presented American Society of Anesthesiologists physical status (ASA) score 3 or above (odds ratio 19.268; 95\%CI 2.523 - 147.132) and surgery for necrotizing enterocolitis/gastrointestinal perforation(OR 5.291; 95\%CI 1.962 - 14.266), compared to those who did not. Conclusion: The overall in-hospital mortality of $6.4 \%$ is within the prevalence reported for developed countries. Establishing ASA score 3 or above and necrotizing enterocolitis/gastrointestinal perforation as independent risk factors for early mortality in neonatal surgery may help clinicians to more adequately manage this high risk population.

Keywords: Mortality. Surgery. Anesthesia, general. Risk factors. Outcomes assessment. Infant, newborn. 


\section{Resumo}

Objetivo: As intervenções anestésicas/cirúrgicas em recém-nascidos permanecem procedimentos perigosos, dada a vulnerabilidade dos pacientes nesta população pediátrica. O objetivo foi determinar os fatores pré e intraoperatórios associados com a mortalidade aos 30 dias de pós-operatório e descrever os resultados de mortalidade hospitalar após cirurgia neonatal sob anestesia geral no nosso centro. Métodos: Os recém-nascidos submetidos à anestesia geral para cirurgia durante um período de 11 anos (2000 - 2010) no nosso centro de atendimento pediátrico terciário foram identificados retrospectivamente utilizando a base de dados da unidade de terapia intensiva pediátrica. Foi utilizado o método de regressão logística múltipla para identificar os fatores de risco independentes pré e intraoperatórios associados com a mortalidade aos 30 dias de pós-operatório. Resultados: Das 437 crianças do estudo (mediana de 37 semanas de idade gestacional e de 2.760 gramas de peso ao nascer), 28 (6,4\%) pacientes morreram antes da alta hospitalar. Destes, 22 pacientes morreram no primeiro mês de pós-operatório. Na regressão logística múltipla, a mortalidade aos 30 dias de pós-operatório foi associada a escore de estado físico da Associação Americana de Anestesiologia (ASA) 3 ou superior (odds ratio 19,268, IC95\% 2,523 - 147,132) e a cirurgia para enterocolite necrosante/perfuração gastrointestinal (OR 5,291, IC95\% 1,962 - 14,266). Conclusão: A taxa de mortalidade intra-hospitalar de 6,4\% está dentro da prevalência encontrada em países desenvolvidos. O estabelecimento de classificação ASA 3 ou superior e de enterocolite necrosante/ perfuração gastrointestinal como fatores de risco independentes para mortalidade precoce em cirurgia neonatal pode ajudar os médicos a gerir mais adequadamente essa população de alto risco.

Palavras-chave: Mortalidade. Cirurgia. Anestesia geral. Fatores de risco. Avaliação de resultados. Recém-Nascido.
Introduction

The surgical neonate, i.e. the newborn submitted to surgery between birth and 28 days of life, requires care in specialized centers offering high-risk neonatal support, with neonatology and pediatric surgical specialties. These patients are often immature and very ill ${ }^{1}$, presenting associations of several risk factors such as preterm birth, low birth weight, chromosomal defects, genetic syndromes or serious illness with multiple organ dysfunction, and thus require management in highly dedicated neonatal intensive care units.

In the context of gestational age at birth, birth weight and neonatal pathological conditions, certain adverse early variables - such as decreasing gestational age, decreasing birth weight and critically compromised neonatal health status, specifically in the presence of surgical life-threatening conditions mainly related to immaturity and low birth weight have been recognized for increasing risk of poorer health outcomes for neonatal and infant morbidity and mortality ${ }^{2,3}$. Assessing clinical risk factors that can potentially influence postoperative course is therefore appropriate to better understand and improve outcomes. However, in literature these aspects have not yet been addressed, except for some studies limited to a single pathology or surgery. Specifically, no data are available on predictors of post-operative mortality in neonates undergoing general anesthesia for a broad range of surgical pathologies.

In an era of decrease in maternal/child mortality among United Nation member countries, namely Portugal ${ }^{3-7}$ and Brazil ${ }^{3,4,7,8}$, the aim of this study was to determine clinical pre and intraoperative risk factors associated with 30-day postoperative mortality and describe in-hospital mortality following neonatal surgery under general anesthesia in a tertiary Portuguese care center.

\section{Methods}

Permission to review patient's data was obtained from the Hospital's Institutional 
Review Board, according to the institutional policy for protected health information. A retrospective study was carried out of all newborn patients subject to general anesthesia for surgical procedures admitted to the Intensive Care Unit (PICU) of the Coimbra's Pediatric Hospital $(\mathrm{CPH})$ between January $1^{\text {st }}$ 2000 and December $31^{\text {st }} 2010$.

Study participants were identified from clinical records of all neonates admitted to the PICU. Eligible cases were defined as those that met the following criteria: newborn patients submitted to surgical procedures under general anesthesia during the neonatal period ( 0 - 28 days of life), admitted to the PICU either preoperatively or in the first post-operative hours and whose surgery was completed at $\mathrm{CPH}$.

Our hospital's PICU is a regional tertiary care unit for approximately 100 newborn patients per year, including all surgical cases. The central region of Portugal is served by two other tertiary affiliated perinatal hospitals clustered with our tertiary medical and surgical PICU and by a specialized neonatal and pediatric emergency transport service to transfer newborn infants at risk from other health units within our wide area of referrals. $\mathrm{CPH}$ has a combined pediatric and neonatal intensive care unit with a team of health care providers highly specialized in the management of neonatal life-threatening conditions, including pediatric anesthesiologists. All subspecialties of neonatal surgery are available in this hospital except for open-heart cardiac surgery that is performed in one affiliated adult hospital. All professionals who work in the PICU and in the operating room, including surgeons and anesthesiologists, are specialized, highly skilled and exclusively dedicated to the pediatric field.

Patient demographics, pre, intra and postoperative details and outcome were collected.

Outcomes were predictors of death within 30 days of surgery and in-hospital mortality, defined as death occurring after surgery during hospital stay.

Some continuous data (gestational age, birth weight, Apgar score) were dichotomized into categorical data according to break-points of severity used in literature ${ }^{9,10}$, for statistical analysis. Analysis of birth weight was performed using gender- and gestation-specific charts previously described $^{11}$. Acquired surgical indication was defined as surgical conditions that evolved after birth. A V grade post-operative complication in the Clavien-Dindo classification was defined as resulting in death of the patient ${ }^{12}$. The variable of days in PICU was defined as number of days spent in our PICU system.

\section{Statistical analysis}

Statistical analyses were performed using SPSS Software Version $19.0^{\circ}$ for Windows (SPSS Inc., Chicago, IL, USA). Categorical data are summarized as absolute values (percentage). Continuous data are presented as median and range.

Initially, all factors potentially associated with 30-day post-operative mortality (listed in results Table 4) were analyzed (presence vs. absence) using $\chi^{2}$ or Fisher's exact tests as appropriate. Factors significant on this analysis ( $\mathrm{p}<0.05)$, and which were not clinically related to other significant variables, were entered into a logistic regression model using backward stepwise (conditional) method in SPSS statistical software. Hosmer-Lemeshow and omnibus tests were performed to determine the goodness of fit and performance of the model, respectively. Variables with odds ratio $95 \%$ confidence intervals (CI) that did not cross 1 were considered to have an independent and significant association with mortality.

Evidence of association was set at $\mathrm{p}<0.05$.

\section{Results}

\section{Patient and Operative Characteristics}

Overall, of 1,055 newborns admitted to the PICU between January $1^{\text {st }} 2000$ and December $31^{\text {st }} 2010,437$ (41\%) patients met inclusion criteria. In these neonates, 558 interventions were performed under general anesthesia, for a total of 636 surgical procedures.

Table 1 refers to information regarding characteristics at birth. From the wide list of procedures performed, some interventions 
Table 1 - Birth characteristics among the 437 infants.

Tabela 1 - Características ao nascer dos 437 pacientes.

\begin{tabular}{lcc}
\hline Characteristic & $\mathrm{n}$ & $\%$ \\
\hline Gender & & \\
Male & 244 & 56 \\
Female & 193 & 44 \\
Birth weight, grams (median 2.760, range 440-4350) & & \\
$<1.500$ & 62 & 14 \\
$1.500-2.499$ & 105 & 24 \\
$\geq 2.500$ & 270 & 62 \\
Gestational age, weeks (median 37, range 24-41) & & \\
$<32$ & 66 & 15 \\
$32-36$ & 112 & 26 \\
$\geq 37$ & 259 & 59 \\
Birth weight/gestational age & & \\
Percentile $<10$ & 67 & 14 \\
Percentile $>90$ & 17 & 4 \\
Percentile 10 - 90 & 353 & 82 \\
Apgar & & \\
$7-10$ at 5 minutes & 412 & 94 \\
$<7$ at 5 minutes & 16 & 4 \\
Missing & 9 & 2 \\
Congenital malformations & 356 & 82 \\
Syndromes, associations or genetic anomalies & 49 & 11 \\
Myelomeningocele and Chiari II & 16 & - \\
VATER/VACTERL & 11 & - \\
Trisomy 21 & 11 & - \\
Trisomy 18 & 1 & - \\
Charge & 2 & - \\
Treacher collins & 2 & - \\
Cystic fibrosis & 2 & - \\
Other* & 4 & - \\
\hline & &
\end{tabular}

*indicates Lenz, Alagille, Beckwith Wiedemann and Goldenhar syndromes: 1 of each.

*indica síndromas de Lenz, Alagille, Beckwith Wiedemann e Goldenhar: 1 de cada.

Table 2 - Most relevant surgical conditions among the 636 surgical procedures performed.

Tabela 2 - Situações cirúrgicas mais relevantes entre as 636 operações realizadas.

\begin{tabular}{lc}
\hline Surgical condition & $\mathrm{n}$ \\
\hline Congenital diaphragmatic defects & 52 \\
Esophageal atresia /tracheoesophageal fistula & 48 \\
Necrotizing enterocolitis/gastrointestinal perforation & 39 \\
Small bowel obstruction or atresia & 80 \\
Anorectal malformations & 31 \\
Hirschsprung disease & 18 \\
Omphalocele & 26 \\
Gastroschisis & 38 \\
Bladder extrophy & 8 \\
Congenital cystic adenomatoid malformation of the lung & 5 \\
Hydrocephalus & 68 \\
Myelomeningocele & 32 \\
Choanal atresia & 8 \\
Congenital tumors & 8 \\
Patent ductus arteriosus & 10 \\
\hline
\end{tabular}


stand out given their prevalence or severity, namely those for conditions listed in Table 2.

Most interventions (85\%) were performed in the operating room using balanced anesthesia, intravenous anesthesia or inhalational anesthesia, however, in selected cases, newborn infants underwent operative procedures in the PICU under intravenous anesthesia. These cases included newborns subject to special techniques (namely high-frequency oscillatory ventilation in the case of some diaphragmatic hernias), critically ill newborns too unstable to transport to the operating room or those receiving simple interventions such as central vascular access placement, balloon atrial septostomy for congenital heart disease or chest tube placement for pleural effusions. Intravenous anesthesia was usually achieved using a combination of midazolam and fentanyl and inhalational anesthesia with sevoflurane.

Over the study period, while always following the state of the art, surgical neonates handling techniques did not change significantly and in-hospital mortality remained stable.

Median PICU stay was 7 days (range 1 204). Ten patients suffered from a ClavienDindo grade $V$ post-operative complication within 30 days of surgery, with death occurring outside this time period in only one case $(\mathrm{p}<0.001)$.

\section{In-hospital mortality}

Twenty-eight of the 437 patients (6.4\%) died in-hospital. Of those, 22 patients died within the first post-operative month (30-day mortality), including 9 patients who died up to the second post-operative day. Causes of in-hospital death are presented in Table 3; almost two-thirds (61\%) of all in-hospital deaths were preterm related.

\section{Initial screening of factors associated with 30-day mortality}

Within 30 days of surgery, there were 22 deaths (5\%). Significant differences between these patients and patients who survived were detected (Table 4).

Screening analysis of adverse outcome showed that the presence of preterm birth (under 37 weeks gestation), low birth weight (under2,500g), verylowbirth weight $(<1500 \mathrm{~g})$ in very preterm (under 32 weeks gestation), large for gestational age, acquired surgical indication, American Society of Anesthesiologists physical status (ASA) score 3 or above in at least one procedure, balanced or intravenous anesthesia, abdominal surgery, necrotizing enterocolitis and need for intraoperative cardiopulmonary resuscitation maneuvers were each significantly associated with a higher risk of mortality (Table 4), compared with its absence. On the other hand, several other clinical characteristics, presented in Table 4, also tested in the initial screening analysis, were not significantly associated with 30 -day postoperative mortality.

\section{Logistic regression analysis}

Characteristics not significantly associated with mortality or showing strong clinical relation to other more representative variables were excluded from our model of logistic regression analysis to avoid reducing statistical

Table 3 - Causes of in-hospital postoperative death.

Tabela 3 - Causas de morte pós-operatória intrahospitalar.

\begin{tabular}{lcc}
\hline Cause of death & All $(\mathrm{n}=28)$ & 30-day mortality $(\mathrm{n}=22)$ \\
\hline Peritonitis/Abdominal sepsis & 12 & 10 \\
Central nervous system hemorrhage & 5 & 4 \\
Respiratory insufficiency & 4 & 2 \\
Cardiac insufficiency & 2 & 2 \\
Neonatal sepsis & 2 & 2 \\
Hypoventilation of central cause & 1 & - \\
Acute renal insufficiency & 1 & 1 \\
Abdominal compartment syndrome & 1 & 1 \\
\hline
\end{tabular}


relevance. Specifically, the confounders preterm birth, balanced anesthesia, abdominal surgery and cardiopulmonary resuscitation were not included, since they were clinically related to one or more of the selected characteristics (respectively to very preterm birth, intravenous anesthesia, necrotizing enterocolitis/gastrointestinal perforation and ASA score 3 or above).

Our model, composed by very low birth weight in very preterm, ASA score 3 or above, acquired surgical indication, intravenous anesthesia and necrotizing enterocolitis/ gastrointestinal perforation, was finalized in four steps by the backward stepwise method, and showed good performance, and was deemed reliable respectively by omnibus $\left(\mathrm{X}_{(2)}^{2}=35.187 ; \mathrm{p}<0.001\right)$ and HosmerLemeshow $\left(\mathrm{X}_{(2)}^{2}=0.096 ; \mathrm{p}=0.953\right)$ tests.

Table 5 summarizes the two independent risk factors (ASA score $\geq 3$ and necrotizing

Table 4 - Characteristics of infants who died within 30 days of surgery and patients who did not and their association with 30-day mortality in the initial screening statistical analysis.

Tabela 4 - Características dos recém-nascidos que morreram nos primeiros 30 dias de pós-operatório e dos que não morreram e sua associação com morte na análise estatística inicial.

\begin{tabular}{|c|c|c|c|c|}
\hline \multirow[b]{2}{*}{ Factors } & \multicolumn{2}{|c|}{ 30-day mortality } & \multirow[b]{2}{*}{$\begin{array}{c}\text { OR } \\
(95 \% \mathrm{Cl})^{*}\end{array}$} & \multirow[b]{2}{*}{$p$-value } \\
\hline & $\begin{array}{c}\text { Yes }(n=22) \\
n\end{array}$ & $\begin{array}{c}\text { No }(n=415) \\
n\end{array}$ & & \\
\hline \multicolumn{5}{|l|}{ Patient characteristics at birth } \\
\hline Male gender $(n=244)$ & 15 & 229 & $1.7(0.7-4.4)$ & NS \\
\hline GA < 37 weeks $(n=178)$ & 14 & 164 & $2.7(1.1-6.5)$ & $0.025^{* * *}$ \\
\hline$B W<2,500 \mathrm{~g}(\mathrm{n}=167)$ & 15 & 152 & $3.7(1.5-9.3)$ & $0.003^{* * *}$ \\
\hline BW $<1,500 \mathrm{~g}$ and $\mathrm{GA}<32$ weeks $(\mathrm{n}=56)$ & 9 & 47 & $5.4(2.2-13)$ & $<0.001^{* * *}$ \\
\hline SGA $(<10$ th percentile) $(n=67)$ & 6 & 61 & $2.2(0.8-5.8)$ & NS \\
\hline LGA (> 90th percentile) $(n=17)$ & 3 & 14 & $4.5(1.2-17)$ & $0.048^{* * *}$ \\
\hline More than 1 congenital malformation $(n=91)$ & 3 & 88 & $0.6(0.17-2)$ & NS \\
\hline \multicolumn{5}{|l|}{ Patient characteristics at surgery } \\
\hline 1st operation at $<8$ days of life $(n=309)$ & 12 & 297 & $0.48(0.2-1)$ & NS \\
\hline More than 1 anesthetic/surgical intervention $(n=95)$ & 4 & 91 & $0.8(2.6-2.4)$ & NS \\
\hline Acquired surgical indication $(n=99)$ & 12 & 87 & $4.5(1.9-11)$ & $<0.001^{* * *}$ \\
\hline ASA score $\geq 3(n=207)$ & 21 & 186 & $25.8(3-194)$ & $<0.001^{* * *}$ \\
\hline \multicolumn{5}{|l|}{ Anesthesia** (each vs. others) } \\
\hline Balanced $(n=372)$ & 15 & 357 & $0.35(0.14-0.9)$ & $0.022^{* * *}$ \\
\hline Intravenous ( $\mathrm{n}=75$ ) & 8 & 57 & $3(1.2-7.3)$ & $0.014^{* * *}$ \\
\hline Inhalational $(\mathrm{n}=8)$ & 1 & 7 & $2.8(0.3-23.6)$ & NS \\
\hline \multicolumn{5}{|l|}{ Surgery for (each vs. others) } \\
\hline Esophageal atresia $(n=42)$ & 1 & 41 & $0.4(0.06-3)$ & NS \\
\hline Abdominal wall defects $(n=49)$ & 3 & 46 & $1.3(0.4-4.4)$ & NS \\
\hline Diaphragmatic hernia $(n=42)$ & 2 & 40 & $0.9(0.2-4)$ & NS \\
\hline Necrotizing enterocolitis $(n=31)$ & 8 & 23 & $9.7(3.7-26)$ & $<0.001^{* * *}$ \\
\hline Duodenal obstruction $(n=25)$ & 0 & 25 & $0.94(0.92-0.96)$ & NS \\
\hline Small bowel atresia $(n=16)$ & 0 & 16 & $0.96(0.94-0.98)$ & NS \\
\hline Anorectal malformations $(n=30)$ & 1 & 29 & $0.6(0.08-5)$ & NS \\
\hline Hirschsprung disease $(n=6)$ & 0 & 6 & $0.99(0.97-1)$ & NS \\
\hline Hydronephrosis $(n=4)$ & 1 & 3 & $6.5(0.65-66)$ & NS \\
\hline Cardiac malformations $(n=31)$ & 1 & 30 & $0.6(0.08-4.7)$ & NS \\
\hline Acquired hydrocephalus $(n=30)$ & 1 & 29 & $0.6(0.08-5)$ & NS \\
\hline Myelomeningocele $(n=27)$ & 0 & 27 & $0.93(0.91-0.96)$ & NS \\
\hline Abdominal surgery $(n=225)$ & 19 & 206 & $6.4(1.9-22)$ & $0.001^{* * *}$ \\
\hline Thoracic surgery $(n=62)$ & 0 & 62 & $0.85(0.82-0.9)$ & NS \\
\hline Duration of surgery $>2 h(n=177)$ & 7 & 170 & $0.67(0.27-1.7)$ & NS \\
\hline Intraoperative CPR $(\mathrm{n}=2)$ & 2 & 0 & $1.1(0.96-1)$ & $0.002^{* * *}$ \\
\hline
\end{tabular}

OR: odds ratio; Cl: confidence interval; *association of presence vs. absence of each factor with 30-day mortality; **in at least 1 intervention; GA: gestation age; BW: birth weight; SGA: small for gestation age; LGA: large for gestation age; ASA score: physical status by the American Society of Anesthesiologists classification system; CPR: cardiopulmonary resuscitation maneuvers; NS: not significant; *** statistically significant.

OR: odds ratio; Cl: intervalo de confiança; *associação da presença vs. ausência de cada fator com a mortalidade aos 30 dias; **em pelo menos uma intervenção; GA: idade de gestação; SGA: pequeno para a idade de gestação; LGA: grande para a idade de gestação; ASA score: estado físico pelo sistema de classificação da Sociedade Americana de Anestesiologia; CPR: manobras de ressuscitação cardiorrespiratória; NS: sem significado estatístico; ***estatisticamente significativo. 
Table 5 - Independent risk factors for 30-day post-operative mortality among pediatric intensive care unit surgical admissions.

Tabela 5 - Fatores de risco independentes para mortalidade aos 30 dias de pós-operatório entre as admissões cirúrgicas na unidade de terapia intensiva pediátrica.

\begin{tabular}{|c|c|c|c|}
\hline \multirow[b]{2}{*}{ Risk factor } & \multicolumn{2}{|c|}{ 30-day mortality } & \multirow[b]{2}{*}{$p$-value } \\
\hline & Odds ratio & $95 \% \mathrm{Cl}$ & \\
\hline ASA score 3 or above* & 19.268 & $2.523-147.132$ & 0.004 \\
\hline NEC/Perforation* & 5.291 & $1.962-14.266$ & $<0.001$ \\
\hline
\end{tabular}

Cl: confidence interval; ASA score: physical status by the American Society of Anesthesiologists classification system; *the reference was the absence of the factor; NEC: necrotizing enterocolitis.

Cl: intervalo de confiança; ASA score: estado físico pelo sistema de classificação da Sociedade Americana de Anestesiologia; *a referência usada foi a ausência do fator; NEC: enterocolite necrosante.

enterocolitis/gastrointestinal perforation in operated newborns) for early mortality within 30 days of surgery. Very low birth weight in very preterm, acquired surgical indication and intravenous anesthesia lost significance $(\mathrm{p} \geq 0.05)$.

\section{Discussion}

In a large cohort of critically ill neonates undergoing anesthetic/surgical procedures at our center, the present study was the first to demonstrate that both ASA score 3 or above and necrotizing enterocolitis/gastrointestinal perforation were independent risk factors for 30-day post-operative mortality in the specific population of surgical neonates. Moreover, we found that the overall in-hospital mortality was $6.4 \%$. The commonest cause of mortality was multiple organ dysfunction, usually preterm related.

Compared with patients who survived the first post-operative month, deceased patients within this time period were more premature, lighter and sicker (with worse physical status) and were more likely to have had abdominal surgery for acquired illnesses associated with preterm birth, such as necrotizing enterocolitis/gastrointestinal perforation. Probably given their worse physical status, intraoperative cardiopulmonary resuscitation maneuvers were more likely needed during their procedures. More than one third of deaths occurred within the first post-operative month but mortality was mostly due to complications related to the previous illness. Neonatal anesthesia and surgery in this setting are likely to have by themselves a negative impact on post-operative condition, which in turn may influence survival.
In our series, there was an overall discharge mortality of $6.4 \%$ and a 30 -day mortality of $5 \%$. This overall mortality, relating to a surgical PICU population of risk, is within the prevalence reported for developed countries, which is usually below $10 \%{ }^{13}$. To place results in context, nowadays, global neonatal surgical mortality is variable, especially depending on the level of development of the country. Two large studies reported $6.7^{14}$ and $7.5 \%{ }^{13}$ in South Korea and Japan, respectively, which compares favorably to 35 and $45 \%$ in studies from India ${ }^{15}$ and Nigeria ${ }^{16,17}$, respectively.

In our cohort, despite the large number of patients with disabling illness (45.5\% classified as ASA 3 or higher), there were no intraoperative deaths. This probably reflects the global improvement in healthcare in Portugal recognized in the 2011 report of the Organization for Economic Co-operation and Development (OECD) ${ }^{3}$, which showed an impressive decrease in neonatal mortality rates despite the increase of preterm births ${ }^{3,5,18}$. The achievements of successful outcomes in this group of complicated patients seem to be related to the availability of very specialized resources, namely those provided by dedicated medical teams, including neonatologists and pediatric anesthesiologists, and well-equipped hospital facilities, while key indicators of progress. Thus, optimal stabilization procedures and access to specialist care will probably improve outcome for neonates undergoing neonatal surgery in general $^{19}$.

A number of factors were associated with 30-day post-operative mortality on the initial statistical screening, but only two remained 
significant on our model of multiple logistic regression: ASA score 3 or above and necrotizing enterocolitis/gastrointestinal perforation. Regarding the first factor, high ASA score was the strongest predictor of mortality, as was expected ${ }^{20}$, thus confirming the accuracy of this physical status scoring system. Thirtyday post-operative mortality was 19 times greater among children with ASA scores 3 or above. Regarding necrotizing enterocolitis, which is known to be a life-threatening condition mainly related to immaturity and low birth weight ${ }^{21-23}$, our results were largely consistent with others that report post-operative high morbidity and mortality following surgery for this condition, given its progression to abdominal sepsis with multiorgan failure ${ }^{24-26}$. In the current study, necrotizing enterocolitis was found to be the leading primary cause of in-hospital mortality following neonatal surgery, accounting for $41 \%$ of all causes of 30-day post-operative mortality. Additionally, risk for 30-day post-operative death was found to be 5 times greater.

Studies have also shown that other factors associated with mortality in infants include low birth weight and preterm birth $^{3,27}$. These factors are known to act by themselves as risk characteristics for poor health outcomes, particularly at the lower end of viability of gestational age and birth weight ${ }^{28}$. However, the impact of these demographics on neonatal surgery mortality remains under-researched, even though they are more commonly found in critically ill patients than in other newborns. Although the initial statistical screening showed significant differences in 30-day mortality in the presence of very low birth weight in very preterm compared with the absence of the factor, our results do not support the hypothesis of an independent causal association between these variables, suggesting involvement of other factors $^{29}$. A possible explanation for the lack of independent association of very low birth weight in very preterm with 30 -day mortality found in our series is the increased healthcare infant support offered in Portugal in the study period, recently addressed by the
2011 OECD indicators ${ }^{3}$, which may have lowered the incidence of certain events pertaining to the surgery experience, such as perioperative hypothermia, dehydration, hypotension, electrolyte imbalances and increased transfusion needs, to which this group is more susceptible and that are known to worsen outcomes.

There were several strengths to the present study. Firstly, very few studies can be found in literature addressing specifically the surgical infant and neonatal populations ${ }^{14-17,30,31}$ and none focuses on the impact of clinical risk factors on outcomes or includes such a broad range of surgical pathologies. The present study aims to fulfill this gap. Secondly, our work is representative of the Portuguese neonatal surgical population of tertiary PICUs, given our wide area of influence and the similarity of demographic and clinical characteristics provided in previous descriptive studies of a southern Portugal tertiary PICU ${ }^{5,31}$. Thirdly, it is based on a very complete data set that prospectively registers numerous demographic and clinical details of newborns admitted to our PICU. This enabled collection of potential risk factors of birth and clinical characteristics.

However, there were some limitations to the present study. Although the information in the PICU database was gathered prospectively, the design of our study was retrospective, so we relied on accurate record keeping, which may have introduced misclassification bias. Also, our study population is limited to the patients admitted at our tertiary intensive care unit, overlooking on one hand the higher mortality expected in open-heart procedures operated outside our pediatric hospital and, on the other hand, the lower mortality of operated newborns without critical disease or risk factors serious enough to justify intensive care admission.

\section{Conclusions}

We have documented an incidence of inhospital overall mortality of $6.4 \%$ in infants undergoing neonatal surgery which, although found to be within the prevalence reported for developed countries, may allow further 
improvement. In-hospital mortalitywas found to be particularly associated with preterm related illnesses, such as necrotizing enterocolitis, and with ASA score 3 or above. Establishing these conditions as independent risk factors for early mortality in neonatal surgery may help clinicians to more adequately manage this high-risk population and to diminish prognosis uncertainty allowing better understanding of risk and hence better communication to parents.

\section{References}

1. Boat AC, Sadhasivam S, Loepke AW, Kurth CD. Outcome for the extremely premature neonate: how far do we push the edge? Pediatr Anesth 2011; 21(7): 765-70.

2. Boyle EM, Poulsen G, Field DJ, Kurinczuk JJ, Wolke D, Alfirevic Z, et al. Effects of gestational age at birth on health outcomes at 3 and 5 years of age: population based cohort study. BMJ 2012; 344: e896.

3. OECD (2011). Health at a Glance 2011: OECD Indicators Disponível em: http://dx.doi.org/10.1787/health_glance2011-en. (Acessado em 27 de setembro de 2012).

4. Muldoon KA, Galway LP, Nakajima M, Kanters S, Hogg RS, Bendavid E, et al. Health system determinants of infant, child and maternal mortality: A cross-sectional study of UN member countries. Global Health 2011; 7: 42.

5. Neto MT. Perinatal care in Portugal: effects of 15 years of a regionalized system. Acta Paediatr 2006; 95(11): 1349-52.

6. Rocha G, Saldanha J, Macedo I, Areias A, Graça A, Tomé $\mathrm{T}$. [Conditions for neonatal resuscitation in Portuguese delivery rooms: a national survey (2009)]. Acta Med Port 2011; 24 Suppl 2: 213-22. Portuguese.

7. Reis ZS, Pereira AC, Correia RJ, Freitas JA, Cabral AC, Bernardes J. [Analysis of maternal and child health indicators: the parallel between Portugal and Brazil]. Rev Bras Ginecol Obstet 2011; 33(9): 234-9. Portuguese.

8. Mendes Ada C, Sá DA, Miranda GM, Lyra TM, Tavares RA. [The public healthcare system in the context of Brazil's demographic transition: current and future demands]. Cad Saúde Pública 2012; 28(5): 955-64. Portuguese.

9. Lee HC, Subeh M, Gould JB. Low Apgar score and mortality in extremely preterm neonates born in the United States. Acta Paediatr 2010; 99(12): 1785-9.

10. Martin JA, Hamilton BE, Sutton PD, Ventura SJ, Mathews TJ, Kirmeyer S, et al. Births: final data for 2007. Natl Vital Stat Rep 2010; 58(24): 1-85.

11. Olsen IE, Groveman SA, Lawson ML, Clark RH, Zemel BS. New intrauterine growth curves based on United States data. Pediatrics 2010; 125(2): e214-24.

12. Dindo D, Demartines N, Clavien PA. Classification of surgical complications: a new proposal with evaluation in a cohort of 6336 patients and results of a survey. Ann Surg 2004; 240(2): 205-13.
13. Taguchi T. Current progress in neonatal surgery. Surg Today 2008; 38(5): 379-89.

14. Lee EJ, Choi KJ. Mortality Analysis of Surgical Neonates: A 20-year Experience by A Single Surgeon. J Korean Assoc Pediatr Surg 2006 Disponível em: http:// www.koreamed.org/SearchBasic.php?RID=0053JKAP $\mathrm{S} / 2006.12 .2 .137 \& \mathrm{DT}=1$. (Acessado em 27 de setembro de 2012).

15. Gangopadhyay AN, Upadhyaya VD, Sharma SP. Neonatal Surgery : A Ten Year Audit from a University Hospital. Indian J Pediatr 2008; 75(10): 1025-30.

16. Chirdan LB, Ngiloi PJ, Elhalaby EA. Neonatal surgery in Africa. Semin Pediatr Surg 2012; 21(2): 151-9.

17. Faponle AF, Sowande OA, Adejuyigbe O. Anesthesia for neonatal surgical emergencies in a semi-urban hospital, Nigeria. East Afr Med J 2004; 81(11): 568-73.

18. Ventura MT, Gomes Mdo C. [Descriptive analysis of maternal and neonatal characteristics in the maternity of the Dona Estefânia Hospital between 2005 and 2008]. Acta Med Port 2010; 23(5): 793-802. Portuguese.

19. Davidson A. The future of pediatric anesthesia. Paediatr Anaesth 2012; 22(6): 570-2.

20. Malviya S, Voepel-Lewis T, Chiravuri SD, Gibbons K, Chimbira WT, Nafiu OO, et al. Does an objective systembased approach improve assessment of perioperative risk in children? A preliminary evaluation of the 'NARCO'. Br J Anaesth 2011; 106(3): 352-8.

21. Clark RH, Gordon P, Walker WM, Laughon M, Smith $\mathrm{PB}$, Spitzer AR. Characteristics of patients who die of necrotizing enterocolitis. J Perinatol 2012; 32(3) 199-204.

22. Lee JH. An update on necrotizing enterocolitis: pathogenesis and preventive strategies. Korean J Pediatr 2011; 54(9): 368-72.

23. Thyoka M, de Coppi P, Eaton S, Khoo K, Hall NJ, Curry J, et al. Advanced necrotizing enterocolitis part 1: mortality. Eur J Pediatr Surg 2012; 22(1): 8-12.

24. Chiu B, Pillai SB, Almond PS, Beth Madonna M, Reynolds M, Luck SR, et al. To drain or not to drain: a single institution experience with neonatal intestinal perforation. J Perinat Med 2006; 34(4): 338-41. 
25. Eicher C, Seitz G, Bevot A, Moll M, Goelz R, Arand J, et al. Surgical Management of Extremely Low Birth Weight Infants with Neonatal Bowel Perforation: A Single-Center Experience and a Review of the Literature. Neonatology 2012; 101(4): 285-92.

26. Rakshasbhuvankar A, Rao S, Minutillo C, Gollow I, Kolar S. Peritoneal drainage versus laparotomy for perforated necrotising enterocolitis or spontaneous intestinal perforation: A retrospective cohort study. J Paediatr Child Health 2012; 48(3): 228-34.

27. UNICEF and WHO. Low birthweight: country, regional and global estimates. New York: UNICEF; 2004.

28. Terzic S, Heljic S. Assessing mortality risk in very low birth weight infants. Med Arh 2012; 66(2): 76-9.
29. L Wehby G, Ullrich F, Xie Y. Very Low Birth Weight Hospital Volume and Mortality: An Instrumental Variables Approach. Med Care 2012; 50(8): 714-21.

30. Catré D, Lopes MF, Viana JS, Cabrita AS. Morbimortalidade perioperatória no primeiro ano de idade. Rev Bras Anestesiol. Forthcoming 2014.

31. Neto MT, Tavares MN, Serelha M, Casella P. [The surgical face of a neonatal intensive care unit]. Acta Pediatrica Portuguesa. 2010; 41: 241-5.

Received on: 10/17/12 Final version presented on: 04/03/13 Accepted on: 06/05/13 